\title{
Physiological Effects of Nature on Human Body
}

\author{
Vaidya Rohit Mehta* and Ashutosh Guleri \\ Senior Medical Officer, Himalayan Research Institute for Naturopathy \& Yoga, India \\ *Corresponding author: Vaidya Rohit Mehta, Senior Medical Officer, KAYAKALP(Himalayan Research Institute for Yoga \& \\ Naturopathy), Vivekanand Medical Research Trust, Palampur, Kangra, India
}

\section{Opinion}

Modernization and fast life are attracting the world to city life. Currently more than half of the world population is living in modern, relaxed environment but away from nature and are constantly exposed to stress. As a result of these stressful situations in modern society, relaxing effects of nature are receiving positive attention. Lack of open areas in city and cramped space in high rising apartments are restraining.

Recent research has demonstrated that natural environment plays an integral role in health promotion, and there is a positive relationship between nature-derived stimuli and human health. Ayurveda has mentioned 3 types of mental temperaments
a) Doshas of mind-Satvika,
b) Rajisk,
c) Tamsik.

Each of this has a distinct character of its own. Tamas is state of inertia, rajas denote activity and sattava-a transactive state of mind.

Further, Tamas is a mood of lethargy, indolence, indifference, indisposed to activity. Also, a condition of sloth and sleep with no intellectual conviction to pursue, nor emotional feeling to manifest. A person steeped in tamas lives a dull, inactive life, with minimum responsiveness to the world. Rajas is a state of passion, desirous to achieve and agitated. In other words, a state where an individual bristle with frenzied actions leading to his involvement in affairs of the world. Sattva is a state of thoughts in equinity, serenity of mind and objectivity in actions. In simpler words when a person is poised but mature, contemplative and detached from worldly involvement and excitement. Sattva, rajas and tamas composed in different properties, account for heterogenous variety of human beings. In toto every individual possesses all three unas/temperaments but, they change from time to time and place to place.

At Kayakalp we envisioned to bring health seekers closer to nature to enhance their satvika temperament. To effect this change, gardens full of flowers are developed across the facility. When health seekers visualise flowers, it decreases oxy-haemoglobin (oxy-Hb) concentrations in the prefrontal cortex; enhances parasympathetic nervous activity, which is otherwise increased in relaxed state and suppresses sympathetic nervous activity, that is usually found increased in aroused or stressed state. It also decreases pulse rate and reduces blood pressure, lowers down pain ratings, anxiety and fatigue. Thus, when we are exposed to natural environment, our body reverts to how it should be, and we can name this treatment as "Nature therapy-a set of practice aimed at achieving preventive medical effects". It is achieved through exposure to natural stimuli rendering a state of physiological relaxation and boosts the immune functions to prevent diseases. This therapy is now increasingly recognized as an effective relaxation and stress management tool and has the potential to be more widely adopted as a complementary therapy in the future. 


\section{(c) (i) \\ This work is licensed under Creative \\ Commons Attribution 4.0 License}

To Submit Your Article Click Here: Submit Article

DOI: $10.32474 /$ CTBM.2019.01.000114

\begin{tabular}{c}
$\begin{array}{c}\text { Current Trends on Biotechnology \& } \\
\text { Microbiology }\end{array}$ \\
Assets of Publishing with us \\
- Global archiving of articles \\
- Immediate, unrestricted online access \\
- Rigorous Peer Review Process \\
\hline Current Trends on
\end{tabular}

